\title{
Benchmarking using an index for bullwhip effect mitigation
}

\author{
Sanjay Kumara ${ }^{a^{*}}$ and Abid Haleem ${ }^{b}$
}

${ }^{a}$ Professor, Department of Mechanical Engineering, International Institute of Technology and Management, Murthal-131039, Haryana, India ${ }^{b}$ Professor, Department of Mechanical Engineering, Faculty of Engineering and Technology, Jamia Millia Islamia, New Delhi- 110025, Delhi, India

\section{H R O N I C L E}

\begin{tabular}{l}
\hline Article history: \\
Received April 20, 2015 \\
Received in revised format \\
October 10, 2015 \\
Accepted October 152015 \\
Available online \\
October 162015 \\
\hline Keywords: \\
Bullwhip Effect \\
Bullwhip Effect Mitigation Index \\
Variables of Bullwhip Effect \\
Mitigation \\
Graph Theory and Matrix (GTM)
\end{tabular}

\section{A B S T R A C T}

\begin{abstract}
Bullwhip effect is one of the serious problems caused by uncertainty in supply chain management. Graph theoretical approach has been utilized by some of the authors towards evaluation of various phenomena performance. This paper has been an attempt to develop bullwhip effect mitigation index (BWEMI), which is a single numerical benchmarking index utilizing graph theory and matrix (GTM) method. Review of literature and subsequent discussions with experts to obtain their valuable opinions regarding managing supply chains have been utilized to complement and supplement the variables. Digraph theory has been used to develop various matrices showing interactions among bullwhip effect mitigation factors. The tool so developed may help supply chain managers to analyze and quantify efforts towards bullwhip effect mitigation.
\end{abstract}

(C) 2016 Growing Science Ltd. All rights reserved.

\section{Introduction}

Uncertainty in supply chain leads to numerous crucial problems, one of them is called bullwhip effect that is identified by three dimensions- amplification, phase lag and oscillation. Literature available indicates towards studies conducted to address various issues related to bullwhip effect in supply chains (SCs). Also, it has been identified that many factors contribute to existence of bullwhip effect in supply chains operating in an uncertain environment. Some of them are: demand signal processing, rational decision-making, price variation, lead-time and order batching. Researchers have reported many problems associated with bullwhip effect. However, much research work is not available which talks of bullwhip effect mitigation and it's benchmarking. The present paper is an attempt to develop a framework for considering major factors of bullwhip effect mitigation and interactions among them. Main objective of present study may be stated as to identify important factors that may influence bullwhip effect mitigation of a supply chain from literature review and experts' opinions. An effort has been made to: develop the conceptual framework that mitigates the bullwhip effect; and then develop a type of single numerical index 'Bullwhip Effect Mitigation Index (BWEMI)' which may help

\footnotetext{
* Corresponding author Tel.: +91-9212088155

E-mail address: skbhardwaj19711971@gmail.com (S. Kumar)

(C) 2016 Growing Science Ltd. All rights reserved. doi: $10.5267 /$ j.uscm.2015.10.002
} 
practicing managers in benchmarking the efforts of supply chain managers towards reducing bullwhip effect.

\section{Bullwhip effect mitigation environment}

Bullwhip effect mitigation is accomplished through various variables. These variables are interdependent in totality they provide an effect of mitigation. Thus a concept of bullwhip effect mitigation environment is being undertaken and we would be trying to benchmark this environment using some appropriate methodology. Graph theory and matrix (GTM) method has been employed to develop Bullwhip Effect Mitigation Index. Graph theory had been introduced in 1736 (Euler, 1953). G. Kirchoff established theory utilizations in electrical networks (Kirchoff, 1958); and where as Cayley A. applied trees while he enumerating isomers of saturated hydrocarbons (Cayley, 1857).

The need of quantification of bullwhip effect mitigation environment in a single numerical index has been recognized. Graph theory can be used to analyze the interactions among the variables considered for Bullwhip Effect Mitigation Index by transforming into mathematical equations. Graph theory may be observed consisting of diagraph representation that is a visual presentation of factors and interactions among them. The graph theory has already been applied to find TQM environment maintainability index (Grover et al., 2004), TQM performance evaluation of industries in India (Kulkarni, 2005), Industrial robots selection (Rao and Padmanabhan, 2006), Risk and customer sensitivity Scs (Faisal et al., 2006) and Risk Mitigation index in SC (Faisal et al., 2007).

\section{Variables identification for developing bullwhip effect mitigation index}

The reduction of bullwhip effect to minimum level has always been a cause of concern for supply chain practitioners. To identify major variables an idea emerging session was conducted in which practitioners from industry and experts from academia were appropriately included to discuss bullwhip effect mitigation environment variables. They were provided as the background material taken from literature. The variables so identified were again discussed for their relative importance for developing Bullwhip Effect Mitigation Index and six variables ranked top have been chosen appropriately for this paper which are: Coordination and cooperation among SC members; IT enablement of SC; SC integration; SC information sharing; JIT implementation in production process; and Implementation of strategies to reduce variation in customer demand.

\subsection{Cooperation and coordination among members of SC}

Coordination and cooperation among SC members nay be attributed to IT enablement, SC integration, sharing of information and JIT implementation. Supply chain coordination deals with these dependent entities (suppliers, manufacturers, distributors, retailers and end consumers) jointly perform supply chain activities to achieve their own profits by keeping total supply chain profits in view. SC members may coordinate by utilizing contracts for improved management of buyer-supplier relationships and appropriate management of risk (Arshinder et al., 2011). Coordination and cooperation are required among the SC members to manage activities and resources. (Xu et al., 2001; Holmström, 1997) In absence of proper cooperation and coordination, variability of business activities tends to be amplified moving upstream. (Towill 1996; Lee and Belington, 1992).

\subsection{SC IT enablement}

Lack of Computer networking among members may affect information sharing among members. Unawareness about use of IT in SC may adversely affect implementation of IT in supply chain and information sharing. Allocation of funds for IT enablement is important to avoid or reduce Bullwhip effect. Unreliability of IT infrastructure may be seen as one of the main constraint in IT enablement. 
Security of online information is a big question in the minds of the people involved. In previous researches lack of IT enablement has been found important key driving factor in modeling factors responsible for uncertainty in supply chains and also identified as linkage variable in modeling of causes of bullwhip effect. Usage of IT enabled technology to communicate with faster speed and to improve response time may reduce bullwhip effect (Lee et al., 1997). Benefits of effective IT system are (Mazda, 1998): better financial control; improved operations control; effective communication; effective teamwork; effective decision making; and flatter, leaner and more effective organization structure.

\subsection{Supply chain integration}

Information sharing, coordination and cooperation among SC members and IT enablement may lead to SC integration identified as important variable in quantification of bullwhip effect mitigation environment. Supply chain integration helps in implementation of JIT. By using IT, business processes have become 'inter organizations/supply chains' from 'intra organizations/supply chains' which has increasingly changed firm interactions with customers and suppliers. Collaboration may be necessary for successful SC performance. Recently, numbers of steps have been taken by different industrial sectors to create effectiveness and efficiency through integration of processes and activities towards bullwhip effect reduction (Chen et al., 2007).

\subsection{SC information sharing}

Many researchers have researched on impact of effective sharing information on bullwhip effect. Better performance is seen in terms of bullwhip effect reduction when information sharing is implemented in a SC. (Lee et al., 1997; Lee et al., 2000; Kumar \& Haleem, 2008). Information Sharing has been identified as one of the important variable to achieve effective implementation of just in time approach.

\subsection{JIT implementation in production process}

The capability of environment in which the supply chain operates to implement JIT approach successfully needs to be evaluated critically. The main focus here is reduction of lead-time to minimum level that is an important cause for existence of bullwhip effect as identified from literature discussed earlier. The success of JIT depends upon (Nair, 2002): customer orientation; focus on long term objectives; common company objectives; and all departments work as one team.

The term just in time has been increasingly used in automobile industry whereas 'efficient consumer response' and 'quick response' is used in textile industry (Sugimore et al., 1977; Toyoda, 1987; Salmon, 1993; Fernie, 1994; Stern et al., 1996). These terms aim at reducing variability in SCs for improving profitability at reduced costs and an increased overall performance (Svensson, 2003).

\subsection{Implementation of strategies to reduce variation in customer demand}

Uncertainty in demand has been already identified as main source of bullwhip effect. Demand Uncertainty (flawed demand information) arises from volatile demand or inaccurate forecasts. Different demand patterns (like trend and seasonality) ascertained by different actors in supply chain lead to different production pattern or ordering pattern leading to bullwhip effect which occurs more in case of seasonal products. Every Day Low Pricing is one of the strategies to reduce variation in customer demand. (Simchi-Levi et al., 1999) Everyday low pricing strategy has been successfully employed in companies like Walmart globally and in Subhiksha in India to reduce variability in customer demand.

\section{Analyzing bullwhip effect mitigation environment}

Review of literature and consequent discussions among experts from academia and industry in a session conducted as mentioned above recommend that there have been broadly six most important influencing bullwhip effect mitigation environment of SC. In this paper, these six variables are correlated. The 
quantification and interdependencies of these factors have been analyzed; and it has been proposed to quantify capability of SC towards successful countering bullwhip effect.

\subsection{Representation of Digraph}

Digraph comprises of vertices (non-empty finite set of elements) and arcs (finite family of ordered pairs of elements) (Wilson, 1970). Six variables may be used to represent the digraph for Bullwhip effect mitigation index:

- $\mathrm{R}_{1}$ : Cooperation and coordination among supply chain members

- $\mathrm{R}_{2}$ : IT enablement of SC

- $\mathrm{R}_{3}$ : $\mathrm{SC}$ integration

- $\mathrm{R}_{4}$ : Information sharing in supply chain

- $\mathrm{R}_{5}$ : JIT implementation in production process

- $\mathrm{R}_{6}$ : Implementation of strategies to reduce variation in customer demand

Interplay among the factors has been established with the help of experts' opinions. Structural Self Interaction Matrix (SSIM) is established (Table 1) utilizing four symbols:

A: factor $\mathrm{j}$ interacting towards factor $\mathrm{I}$;

$\mathrm{V}$ : factor $\mathrm{i}$ interacting towards factor $\mathrm{j}$;
$\mathrm{O}$ : factors $\mathrm{j}$ and I not related;

$\mathrm{X}$ : factors $\mathrm{j}$ and I interacting towards each other.

\section{Table 1}

SSIM

\begin{tabular}{cccccc}
\hline & $\mathrm{R}_{6}$ & $\mathrm{R}_{5}$ & $\mathrm{R}_{4}$ & $\mathrm{R}_{3}$ & $\mathrm{R}_{2}$ \\
\hline $\mathrm{R}_{1}$ & $\mathrm{O}$ & $\mathrm{V}$ & $\mathrm{X}$ & $\mathrm{V}$ & $\mathrm{X}$ \\
$\mathrm{R}_{2}$ & $\mathrm{~V}$ & $\mathrm{~V}$ & $\mathrm{~V}$ & \\
$\mathrm{R}_{3}$ & $\mathrm{O}$ & $\mathrm{V}$ & $\mathrm{X}$ & \\
$\mathrm{R}_{4}$ & $\mathrm{O}$ & $\mathrm{V}$ & & \\
$\mathrm{R}_{5}$ & $\mathrm{O}$ & & & \\
\hline
\end{tabular}

SSIM has been transformed into initial reachability matrix (IRM) by replacing V, A, O and X by 0 and 1 in Table 2. The transitivity has been checked as if factor $\mathrm{i}$ leads to factor $\mathrm{j}$ and factor $\mathrm{j}$ leads to factor $\mathrm{k}$, then factor $\mathrm{i}$ would lead to factor $\mathrm{k}$. By considering transitivity final reachability matrix (FRM) is established as tabulated in Table 3. From FRM, digraph for bullwhip effect mitigation index has been developed (shown in Fig. 1) and further relationships have been validated.

Table 2

IRM

\begin{tabular}{ccccccc}
\hline & $\mathrm{R}_{1}$ & $\mathrm{R}_{2}$ & $\mathrm{R}_{3}$ & $\mathrm{R}_{4}$ & $\mathrm{R}_{5}$ & $\mathrm{R}_{6}$ \\
\hline $\mathrm{R}_{1}$ & 1 & 1 & 1 & 1 & 1 & 0 \\
$\mathrm{R}_{2}$ & 1 & 1 & 1 & 1 & 1 & 1 \\
$\mathrm{R}_{3}$ & 0 & 0 & 1 & 1 & 1 & 0 \\
$\mathrm{R}_{4}$ & 1 & 1 & 1 & 0 & 1 & 0 \\
$\mathrm{R}_{5}$ & 0 & 0 & 0 & 0 & 0 & 0 \\
$\mathrm{R}_{6}$ & 0 & 0 & 0 & & & 1 \\
\hline
\end{tabular}

Table 3

FRM

\begin{tabular}{lllllll}
\hline & $\mathrm{R}_{1}$ & $\mathrm{R}_{2}$ & $\mathrm{R}_{3}$ & $\mathrm{R}_{4}$ & $\mathrm{R}_{5}$ & $\mathrm{R}_{6}$ \\
\hline $\mathrm{R}_{1}$ & 1 & 1 & 1 & 1 & 1 & 0 \\
$\mathrm{R}_{2}$ & 1 & 1 & 1 & 1 & 1 & 1 \\
$\mathrm{R}_{3}$ & $1^{*}$ & $1^{*}$ & 1 & 1 & 1 & 0 \\
$\mathrm{R}_{4}$ & 1 & 1 & 1 & 1 & 1 & 0 \\
$\mathrm{R}_{5}$ & 0 & 0 & 0 & 0 & 1 & 0 \\
$\mathrm{R}_{6}$ & 0 & 0 & 0 & 0 & 0 & 1 \\
\hline
\end{tabular}




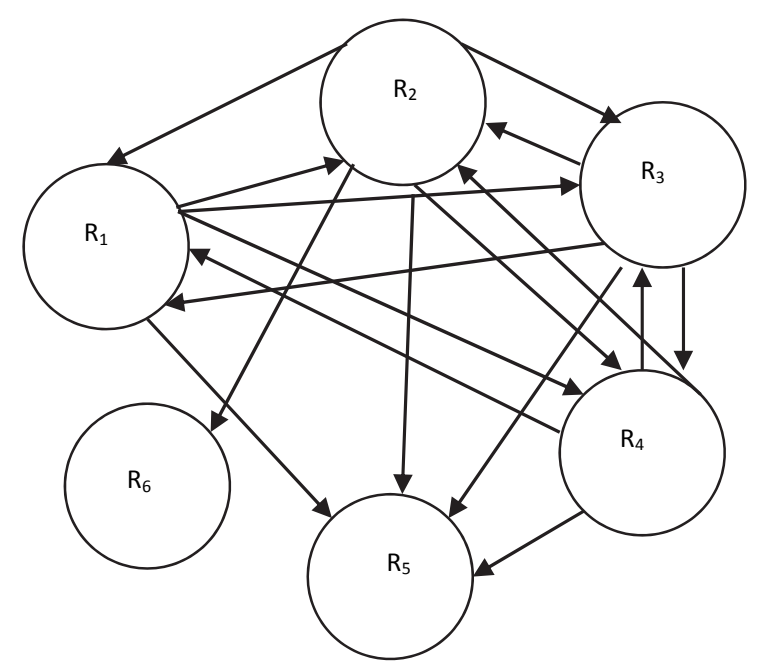

Fig. 1. Digraph of Variables Considered for Developing Bullwhip Effect Mitigation Index

\subsection{Matrix Representation of Bullwhip Effect Mitigation Index}

Matrix representation of BWEMI has been shown below in Table $4 \mathrm{R}_{\mathrm{ij}}$ (off-diagonal elements) showing BWEMI factors' interactions where R represents the effect of individual variable.

\section{Table 4}

\section{Matrix Representation of BWEMI}

\begin{tabular}{lllllll}
\hline & $\mathrm{R}_{1}$ & $\mathrm{R}_{2}$ & $\mathrm{R}_{3}$ & $\mathrm{R}_{4}$ & $\mathrm{R}_{5}$ & $\mathrm{R}_{6}$ \\
\hline $\mathrm{R}_{1}$ & $\mathrm{R} 1$ & $\mathrm{R} 12$ & $\mathrm{R} 13$ & $\mathrm{R} 14$ & $\mathrm{R} 15$ & 0 \\
$\mathrm{R}_{2}$ & $\mathrm{R} 21$ & $\mathrm{R} 2$ & $\mathrm{R} 23$ & $\mathrm{R} 24$ & $\mathrm{R} 25$ & $\mathrm{R} 26$ \\
$\mathrm{R}_{3}$ & $\mathrm{R} 31$ & $\mathrm{R} 32$ & $\mathrm{R} 3$ & $\mathrm{R} 34$ & $\mathrm{R} 35$ & 0 \\
$\mathrm{R}_{4}$ & $\mathrm{R} 41$ & $\mathrm{R} 42$ & $\mathrm{R} 43$ & $\mathrm{R} 4$ & $\mathrm{R} 45$ & 0 \\
$\mathrm{R}_{5}$ & 0 & 0 & 0 & 0 & $\mathrm{R} 5$ & 0 \\
$\mathrm{R}_{6}$ & 0 & 0 & & 0 & 0 & $\mathrm{R} 6$ \\
\hline
\end{tabular}

\subsection{Permanent Representation}

It is evaluated in similar way as determinant is calculated except positive sign replaces all negative signs. BWEMIs' calculations for different SCs are carried out from matrix representations of BWEMI for those SCs. The matrix representation for BWEMI has been performed as follows:

Expanding by $6^{\text {th }}$ and then $5^{\text {th }}$ Row; we get

$$
\mathrm{BWEMI}=R_{6}\left\{R_{5}\left|\begin{array}{llll}
R_{1} & R_{12} & R_{13} & R_{14} \\
R_{21} & R_{2} & R_{23} & R_{24} \\
R_{31} & R_{32} & R_{3} & R_{34} \\
R_{41} & R_{42} & R_{43} & R_{4}
\end{array}\right|\right.
$$

Now, expanding by $1^{\text {st }}$ Row

$$
\mathrm{BWEMI}=R_{6} R_{5}\left[\begin{array}{ccc}
R_{2} & R_{23} & R_{24} \\
R_{1} & R_{3} & R_{34} \\
R_{32} & R_{43} & R_{4}
\end{array}\left|+R_{12}\right| \begin{array}{ccc}
R_{21} & R_{23} & R_{24} \\
R_{31} & R_{3} & R_{34} \\
R_{41} & R_{43} & R_{4}
\end{array}\left|+R_{13}\right| \begin{array}{ccc}
R_{21} & R_{2} & R_{24} \\
R_{31} & R_{32} & R_{34} \\
R_{41} & R_{42} & R_{4}
\end{array}\left|+R_{14}\right| \begin{array}{ccc}
R_{21} & R_{2} & R_{23} \\
R_{31} & R_{32} & R_{3} \\
R_{41} & R_{42} & R_{43}
\end{array} \mid\right]
$$


Expanding each determine by $1^{\text {st }}$ Row; we get

\section{BWEMI}

$$
\begin{gathered}
{\left[\begin{array}{l}
R_{1}\left[R_{2}\left(R_{3} R_{4}+R_{43} R_{34}\right)+R_{23}\left(R_{32} R_{4}+R_{42} R_{34}\right)+R_{24}\left(R_{32} R_{43}+R_{42} R_{3}\right)+R_{12}\left[R_{21}\left(R_{3} R_{4}+R_{43} R_{34}\right)\right.\right. \\
+R_{1}\left[R_{2}\left(R_{3} R_{43}+R_{42} R_{34}\right)+R_{23}\left(R_{32} R_{43}+R_{41} R_{34}\right)+R_{24}\left(R_{31} R_{43}+R_{3} R_{41}\right)+R_{13}\left[R _ { 2 1 } \left(R_{32} R_{4}+R_{42} R_{34}\right.\right.\right. \\
+R_{2}\left(R_{31} R_{4}+R_{41} R_{34}\right)+R_{24}\left(R_{31} R_{42}+R_{41} R_{32}\right)+R_{14}\left[R_{21}\left(R_{32} R_{43}+R_{42} R_{3}\right)+R_{2}\left(R_{31} R_{43}+R_{41} R_{3}\right)\right. \\
+R_{23}\left(R_{31} R_{42}+R_{41} R_{32}\right)
\end{array}\right]} \\
=R_{6} R_{5}\left[\begin{array}{l}
R_{1} R_{2} R_{3} R_{4}+R_{1} R_{43} R_{34} R_{2}+R_{1} R_{23} R_{32} R_{4}+R_{1} R_{23} R_{42} R_{34}+R_{1} R_{24} R_{32} R_{43}+R_{1} R_{24} R_{42} R_{3}+R_{12} R_{21} R_{3} R_{4} \\
+R_{12} R_{21} R_{43} R_{34}+R_{12} R_{23} R_{31} R_{4}+R_{12} R_{23} R_{41} R_{34}+R_{12} R_{24} R_{31} R_{43}+R_{12} R_{24} R_{3} R_{41}+R_{13} R_{21} R_{32} R_{4} \\
+R_{13} R_{21} R_{42} R_{34}+R_{13} R_{2} R_{31} R_{4}+R_{13} R_{2} R_{41} R_{34}+R_{13} R_{24} R_{31} R_{42}+R_{13} R_{24} R_{41} R_{32}+R_{14} R_{21} R_{32} R_{43} \\
+R_{14} R_{21} R_{42} R_{3}+R_{14} R_{2} R_{31} R_{43}+R_{14} R_{2} R_{41} R_{3}+R_{14} R_{23} R_{31} R_{42}+R_{14} R_{23} R_{41} R_{32}
\end{array}\right]
\end{gathered}
$$

\subsection{The Bullwhip Effect Mitigation Index Quantification}

BWEMI may be considered as gauge of SC's capability to deal with bullwhip effect. If BWEMI of SC is conductive, its BWEMI value needs to be higher and vice versa. BWEMI for a system needs to consider values of factors for SC and the degree of interactions among identified factors. $\mathrm{R}_{\mathrm{i}}$ 's and $\mathrm{R}_{\mathrm{ij}}$ ' $\mathrm{s}$ quantification has been necessary for the calculation of permanent function. Kulkarni (2005) utilized questionnaire to assign each weights to each attribute to finally arrive at values of variables. In our case no quantitative ratings had been available as secondary data and ratings have been sorted considering qualitative measure presented Table 5 . Ratings of non-diagonal elements $\mathrm{R}_{\mathrm{ij}}$ showing relative influence between factors may not be directly evaluated. Rao and Padmanabhan (2006) utilized scale suggested by Satty in AHP methodology towards assigning ratings to relative importance between attributes. Ratings may be assigned by experts as per their appropriate interpretation based upon experience and intuition (Faisal, 2006). Table 6 presents qualitative ratings of relative influence of factors.

\section{Table 5}

\section{Rating of BWEMI Variables}

\begin{tabular}{llll}
\hline BWEMI variables Measure & Variable Value $\left(\mathrm{R}_{\mathrm{i}}\right)$ & BWEMI variables Measure & Variable Value $\left(\mathrm{R}_{\mathrm{i}}\right)$ \\
\hline Low- exceptional in nature & 0 & Above Average & 6 \\
Low- extremely & 1 & High & 7 \\
Very low & 2 & Very High & 8 \\
Low & 3 & Extremely High & 9 \\
Below than average & 4 & Exceptionally High & 10 \\
Average & 5 & & \\
\hline
\end{tabular}

\section{Table 6}

Quantification of BWEME Variables considering intensity of Interactions

\begin{tabular}{ll}
\hline Measure & Interdependency $\left(\mathrm{R}_{\mathrm{ij}}\right)$ value \\
\hline Very Weak & 1 \\
Weak & 2 \\
Medium & 3 \\
Strong & 4 \\
Very Strong & 5 \\
\hline
\end{tabular}

SC practitioners may identify a suitable scale; however, final rankings of various SCs will not change because of relative nature of indices for each SC. Considering a typical case of comparisons of two supply chains for which the ratings of BWEMI variables have been given by set of experts in Table 7 and Table 8. 
Table 7

Ratings of BWEMI Variables of "Supply Chain A"

\begin{tabular}{lll}
\hline S. No. & BWEMI Variables & Rating \\
\hline 1 & Cooperation and Coordination among members of supply chain & 8 \\
2 & IT enablement & 6 \\
3 & Supply Chain Integration & 6 \\
4 & Information Sharing & 6 \\
5 & JIT Implementation & 5 \\
6 & Implementation of strategies to reduce variation in customer demand & 6 \\
\hline
\end{tabular}

\section{Table 8}

Ratings of BWEMI Variables of "Supply Chain B"

\begin{tabular}{lll}
\hline S. No. & BWEMI Variables & Rating \\
\hline 1 & Cooperation and Coordination among members of supply chain & 9 \\
2 & IT enablement & 9 \\
3 & Supply Chain Integration & 8 \\
4 & Information Sharing & 9 \\
5 & JIT Implementation & 7 \\
6 & Implementation of strategies to reduce variation in customer demand & 8 \\
\hline
\end{tabular}

\section{Table 9}

Ratings of BWEMI Variables of an "Ideal Supply Chain"

\begin{tabular}{lll}
\hline S. No. & BWEMI Variables & Rating \\
\hline 1 & Cooperation and Coordination among members of supply chain & 10 \\
2 & IT enablement & 10 \\
3 & Supply Chain Integration & 10 \\
4 & Information Sharing & 10 \\
5 & JIT Implementation & 10 \\
6 & Implementation of strategies to reduce variation in customer demand & 10 \\
\hline
\end{tabular}

Table 9 shows rating of BWEMI variables of an ideal supply chain. For better understanding, Table 7 and Table 8 ratings have been represented as web diagrams as shown in Fig. 2 and Fig. 3 (Outer bold line shows the "Ideal Supply Chain" ratings). It may be clearly seen from these web diagrams that gaps between "Supply Chain A" and "Ideal Supply Chain" is higher (Fig. 2) in comparison with gaps between "Supply Chain B" and "Ideal Supply Chain" (Fig. 3). It gives an indication of better capability of "Supply Chain B" relative to "Supply Chain A".
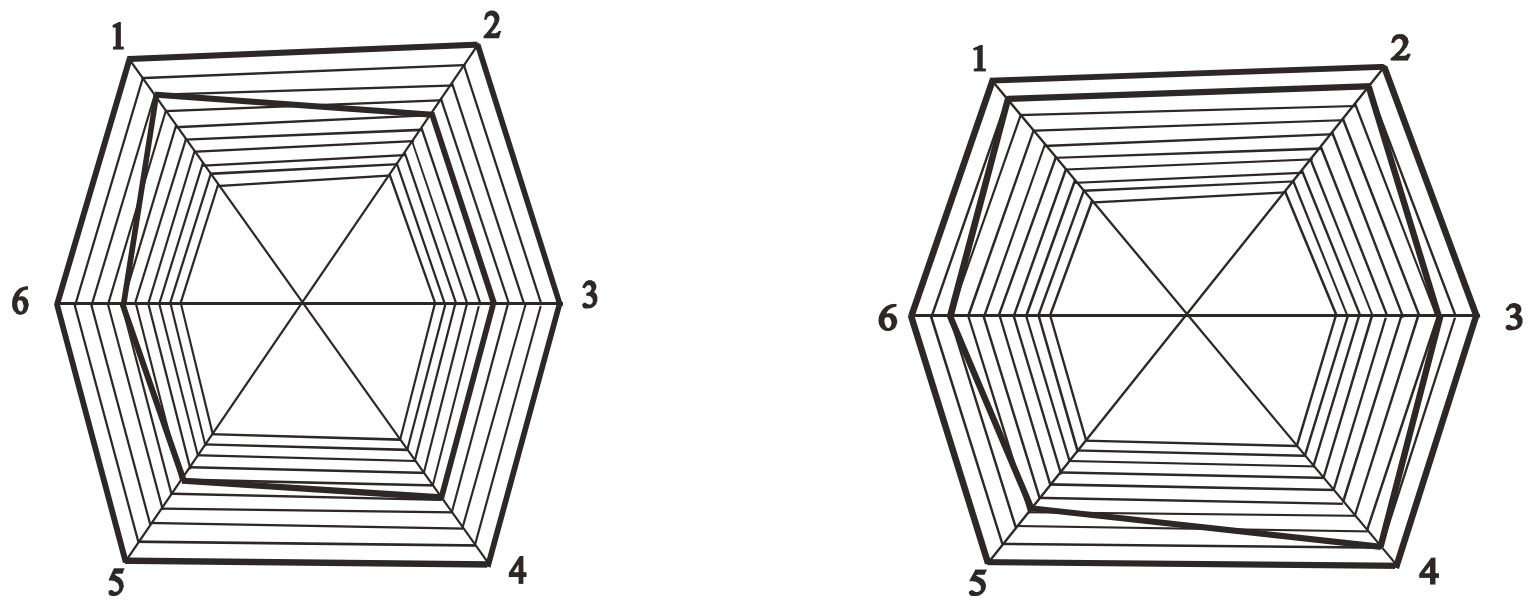

Fig. 2. Web Diagram of Ratings of Variables for "Supply Chain A" Fig. 3. Web Diagram of Ratings of Variables for "Supply Chain B"

The matrix representation of BWEMI for "Supply Chain A", "Supply Chain B" and "Ideal Supply Chain" has been shown in Table.10, Table 11 and Table 12. 
Table 10

Matrix Representation of BWEMI for "Supply Chain A"

\begin{tabular}{lllllll}
\hline & 1 & 2 & 3 & 4 & 5 & 6 \\
\hline 1 & 8 & 4 & 4 & 3 & 5 & 0 \\
2 & 2 & 6 & 3 & 5 & 5 & 4 \\
3 & 2 & 2 & 6 & 3 & 4 & 0 \\
4 & 4 & 2 & 4 & 6 & 5 & 0 \\
5 & 0 & 0 & 0 & 0 & 5 & 0 \\
6 & 0 & 0 & 0 & 0 & 0 & 6 \\
\hline
\end{tabular}

\section{Table 11}

Matrix Representation of BWEMI for "Supply Chain B"

\begin{tabular}{lllllll}
\hline & 1 & 2 & 3 & 4 & 5 & 6 \\
\hline 1 & 9 & 4 & 4 & 3 & 5 & 0 \\
2 & 2 & 9 & 3 & 5 & 5 & 4 \\
3 & 2 & 2 & 8 & 3 & 4 & 0 \\
4 & 4 & 2 & 4 & 9 & 5 & 0 \\
5 & 0 & 0 & 0 & 0 & 7 & 0 \\
6 & 0 & 0 & 0 & 0 & 0 & 8 \\
\hline
\end{tabular}

Table 12

Matrix Representation of BWEMI for "Ideal Supply Chain"

\begin{tabular}{lllllll}
\hline & 1 & 2 & 3 & 4 & 5 & 6 \\
1 & 10 & 4 & 4 & 3 & 5 & 0 \\
2 & 2 & 10 & 3 & 5 & 5 & 4 \\
3 & 2 & 2 & 10 & 3 & 4 & 0 \\
4 & 4 & 2 & 4 & 10 & 5 & 0 \\
5 & 0 & 0 & 0 & 0 & 10 & 0 \\
6 & 0 & 00 & 0 & 0 & 0 & 10 \\
\hline
\end{tabular}

\subsection{Relative Bullwhip Effect Mitigation Index}

Relative bullwhip effect mitigation index may provide SC practitioner information (qualitative in nature) to improve areas contributing towards overall bullwhip effect mitigation capability of SC.

Bullwhip effect mitigation index for various SCs may be evaluated utilizing procedural steps provided in this study and hence different SCs may further be benchmarked considering bullwhip effect mitigation capability. The methodological steps presented have been formulated in order to preserve flexibility in the environment in which SCs are operating by incorporating new variables that may influence SCs' capability towards bullwhip effect mitigation. The BWEMI calculated for "Supply Chain A" is 172560, for "Supply Chain B" is 739648 and for "Ideal Supply Chain" is 1906400. These values may be used by SC managers as guiding index for identifying areas for improvements as also replicated by web diagrams.

\section{Conclusion}

In this paper, the focus had been for modeling bullwhip effect mitigation setting for benchmarking of SCs using a methodology involving graph theory and matrix. With the help of this tool SC practitioners may analyze factors concerning with bullwhip effect mitigation in SCs. The presented framework may be an effective way in improving understanding of bullwhip effect generation in SCs (causing an adverse effect on SC performance) and its mitigation; and hence, 'bullwhip effect mitigation setting' quantification (as an index) will certainly help practitioners to compare and manage SCs better. The framework suggested in this paper is much generalized and not sector specific; and the present work may be further validated using some case studies. Sustainable green, lean and six-sigma concepts have been found very important towards making the firm and supply chain effective and efficient in terms 
of environmental, economic, societal, waste reduction and quality issues (Kumar et al., 2011-12; Kumar et al., 2015; Kumar et al., 2015). Some factors may be incorporated considering sustainable green, lean and six-sigma concept integration in supply chain; and bullwhip effect mitigation may be further evaluated. Technology selection, adoption and absorption have been realized also important for winning over the competition (Kaushik et al., 2014; Kumar et al., 2014; Kumar \& Haleem, 2014). Bullwhip effect needs to be examined in technology oriented supply chains involving management of innovations and knowledge; however, adoption of newer technologies through efficient knowledge management has been identified vital for offering innovative products and services towards gaining competitive advantage over other supply chains (Kumar, 2014 a,b; Kumar et al., 2014; Kumar et al., 2014; Kumar et al., 2015).

\section{References}

Arshinder, K., Kanda, A., \& Deshmukh, S. G. (2011). A review on supply chain coordination: coordination mechanisms, managing uncertainty and research directions. In Supply chain coordination under uncertainty (pp. 39-82). Springer Berlin Heidelberg.

Ball, W. W. R. (1905). Mathematical Recreations and Essays. London.

Cayley, A. (1857). XXVIII. On the theory of the analytical forms called trees. The London, Edinburgh, and Dublin Philosophical Magazine and Journal of Science,13(85), 172-176.

Chen, M. C., Yang, T., \& Li, H. C. (2007). Evaluating the supply chain performance of IT-based interenterprise collaboration. Information \& Management, 44(6), 524-534.

Euler, L. (1741). Solutio problematis ad geometriam situs pertinentis.Commentarii academiae scientiarum Petropolitanae, 8, 128-140.

Faisal, M. N., Banwet, D. K., \& Shankar, R. (2007). Quantification of risk mitigation environment of supply chains using graph theory and matrix methods.European Journal of Industrial Engineering, 1(1), 22-39.

Fernie, J. (1994). Quick response: an international perspective. International Journal of Physical Distribution \& Logistics Management, 24(6), 38-46.

Frank, H., \& Frisch, I. T. (1971). Communication, transmission, and transportation networks.

Grover, S., Agrawal, V. P., \& Khan, I. A. (2004). A digraph approach to TQM evaluation of an industry. International Journal of Production Research, 42(19), 4031-4053.

Holmström, J. (1997). Product range management: a case study of supply chain operations in the European grocery industry. Supply Chain Management: An International Journal, 2(3), 107-115.

$\mathrm{Hu}, \mathrm{T} . \mathrm{C}$. (1969). Integer programming and network flows. Wiscounsin ISCONSIN UNIV MADISON DEPT OF COMPUTER SCIENCES.

Kaushik, A., Kumar, S., Luthra, S., \& Haleem, A. (2014). Technology transfer: enablers and barriersa review. International Journal of Technology, Policy and Management, 14(2), 133-159.

Kirchhoff, G. (1847). Ueber die Auflösung der Gleichungen, auf welche man bei der Untersuchung der linearen Vertheilung galvanischer Ströme geführt wird.Annalen der Physik, 148(12), 497-508.

Kulkarni, S. (2005). Graph theory and matrix approach for performance evaluation of TQM in Indian industries. The TQM magazine, 17(6), 509-526.

Kumar N., Kumar S. and Gahlot P. (2011-12). Critical Factors in Lean Manufacturing System Implementation in Indian Automobile Industry. Journal of Information, Knowledge and Research in Mechanical Engineering, 2(1), 143-155. ISSN: 0975-668X.

Kumar, S., Parveen, R., \& Haleem, A. (2014). Modeling of barriers to technology transfer implementation using system approach. Udyog Pragati,38(2), 1-11.

Kumar, S., \& Haleem, A. (2014). Knowledge management in Indian manufacturing industry: Identification and modeling of enablers. Data Mining and Knowledge Engineering, 6(7), 298-306.

Kumar, S. (2014a). Contextual interactions analytic hierarchy process (CIAHP): introduction and application to analyse interactions among knowledge management implementation capability (KMIC) factors. International Journal of Knowledge and Learning, 9(3), 242-263. 
Kumar, S. (2014). Some application of analytic hierarchy process. Data Mining and Knowledge Engineering, 6(9), 382-384.

Kumar, S., Singh, V., \& Haleem, A. (2014). Knowledge management-enablers and barriers: a questionnaire-based study. International Journal of Knowledge Engineering and Data Mining, 3(1), 31-57.

Kumar, S., Kumar, N., \& Haleem, A. (2014). Contributions in research in the field of innovation management: analysis of critical success factors, benefits and risks. International Journal of Quality and Innovation, 2(3-4), 310-337.

Kumar, S., Kumar, N., \& Haleem, A. (2015). Conceptualisation of sustainable green lean six sigma: an empirical analysis. International Journal of Business Excellence, 8(2), 210-250.

Kumar, S., Luthra, S., \& Haleem, A. (2015). Benchmarking supply chains by analyzing technology transfer critical barriers using AHP approach.Benchmarking: An International Journal, 22(4), 538558.

Kumar, S., Singh, V., \& Haleem, A. (2015). Critical success factors of knowledge management: modelling and comparison using various techniques.International Journal of Industrial and Systems Engineering, 21(2), 180-206.

Lee, H. L., \& Billington, C. (1992). Managing supply chain inventory: pitfalls and opportunities. Sloan management review, 33(3).

Lee, H. L., \& Whang, S. (2000). Information sharing in a supply chain.International Journal of Manufacturing Technology and Management, 1(1), 79-93.

Lee, H. L., Padmanabhan, V., \& Whang, S. (2004). Information distortion in a supply chain: the bullwhip effect. Management science, 50(12 supplement), 1875-1886.

Lee, H. L., Padmanabhan, V., \& Whang, S. (1997). The bullwhip effect in supply chains1. Sloan management review, 38(3), 93-102.

Mazda, F. F. (1998). Engineering management. Addison Wesley.

Nair NC (2002). Production and Operations Management. Tata McGraw Hill Publishing Company Ltd.

Nishat Faisal, M., Banwet, D. K., \& Shankar, R. (2006). Mapping supply chains on risk and customer sensitivity dimensions. Industrial Management \& Data Systems, 106(6), 878-895.

Ore, O. (1967). The four-color problemAcad. Press, New York-London.

Rao, R. V., \& Padmanabhan, K. K. (2006). Selection, identification and comparison of industrial robots using digraph and matrix methods. Robotics and Computer-Integrated Manufacturing, 22(4), 373383.

Salmon, K. (1993). Efficient Consumer Response: enhancing consumer value in the supply chain. Washington DC. 